\title{
A Case of Metastatic Malignant Melanoma who Lung Progressed During Vemurafenib Treatment
}

\section{Vemurafenib Tedavisi Sırasında Akciğer Progresyonu Gösteren Metastatik Malign Melanom Olgusu}

\author{
Ferit Aslan ${ }^{1}$, Kübra Aydın', Banu Öztürk², Umut Demirci ${ }^{1}$ \\ ${ }^{1}$ Dr A. Y. Ankara Onkoloji Eğitim Ve Araştırma Hastanesi, Tıbbi Onkoloji Kliniği, Ankara, Türkiye \\ ${ }^{2}$ Gaziosmanpaşa Üniversitesi, Tıp Fakültesi, Medikal Onkoloji Bilim Dalı, Tokat, Türkiye
}

Doi: $10.5505 /$ aot.2013.30502

\section{ÖZET}

Yetmiş yaşında kadın sağ inguinal bölgede akıntılı şşşliği olması üzerine başvurdu. Lezyon biyopsisi malign melanomla uyumluydu. Toraks ve batın görüntülemelerinde metastaz bulguları mevcuttu. Birinci basamak temozolomid sonrası lezyon bölgesinde progresyon nedeni ile palyatif radyoterapi uygulandı. BRAF-V600E mutasyonu nedeni ile vemurafenib başlandı. Tedavinin ikinci ayında çok iyi kısmi yanıt elde edildi. Tedavinin 5 . ayında sol akciğerde lokal progresyon izlenirken diğer bölgelerde kısmi yanıtı devam ediyordu. Palyatif radyoterapi sonrası vemurafenib tedavisine devam edildi.

Anahtar Kelimeler: Malign melanom; Vemurafenib; Radyoterapi

\begin{abstract}
A 70 year-old women admitted to our hospital with a swelling and discharge of the right inguinal site. Biopsy results was consisted with malignant melanoma. Imaging of thorax and abdomen showed metastatic disease. After first-line temozolamide treatment, palliative radiotherapy was applied to primary site because of progression. After detection of BRAF-V600E mutation, vemurafenib treatment was initiated. Treatment response to vemurafenib was very good partial response after second months of the treatment. Although locally progression of the left lung was seen after fifth months of therapy, partial response remained on the other sites, she was still on the treatment with vemurafenib.
\end{abstract}

Key words: Malignant Melanoma; Vemurafenib; Radiotherapy

\section{Giriş}

İleri evre malign melanomda (MM) 2011 öncesinde beklenen ortanca genel sağkalım (OS) 8-9 ay, 3 y1llık OS oran1 \%15 idi (1). İkibino sonrası tirozin kinaz inhibitörleri (TKİ) (vemurafenib, dabrafenib ve trametinib) ve immünoterapiler (ipilimumab) ile metastatik MM tedavisinde ilk defa OS katkısı gösterilmiştir (1).

BRAF proteini hücrenin büyümesi ve yaşamını devam ettirmesinde rol oynayan RAF kinaz ailesinin bileşenidir. BRAF proteinindeki bir mutasyon bu yolaktaki aşırı sinyal artışına bunun sonucunda da kontrolsüz hücre çoğalmasına neden olur. Kutanöz melanomların \%40-60 kadarı BRAF mutasyonu taşır $(2,3)$. $\mathrm{Bu}$ mutasyonların yaklaşık \%90'1 glutamik asit ile valinin yer değiştirdiği V600E mutasyonunu içermektedir. Diğer aktive edici mutasyonlar BRAF- V600K ve V600R Adressforcorrespondence: Uzm. Dr. Ferit Aslan e-mali: feritferhat21@gmail.com

Available at www.actaoncologicaturcica.com

Copyright @Ankara Onkoloji Hastanesi mutasyonlarıdır. Vemurafenib ve dabrafenib V600E ve V600K mutasyonu taşıyan melanom hücrelerine potent antitümöral etkili ajanlardır $(1,4)$. Bu ajanlar ile elde edilen hizlı yanıt ve OS katkısına rağmen gelişen ilaç direnci en önemli sorundur. Biz burada vemurafenib tedavisinin 5. ayında sistemik hastalık kontrolüne rağmen izole akciğer progresyonu izlediğimiz ve vemurafenib tedavisine devam ettiğimiz metastatik MM'lu olguyu sunmay amaçladık.

\section{Olgu Sunumu}

Yetmiş yaşında kadın 8 aydır devam eden bel ağrıs1, sağ inguinal bölgede şişlik nedeniyle başvurdu. Fizik muayenesinde sol kasıkta kötü kokulu akıntıl1, 5 cm'yi bulan lenfadenopati ile uyumlu kitlesi ve sağ alt ekstremitede ödem mevcuttu. Alt ekstremite hareketleri k1sitlı idi. Diğer sistem bulguları normaldi. Lezyon 


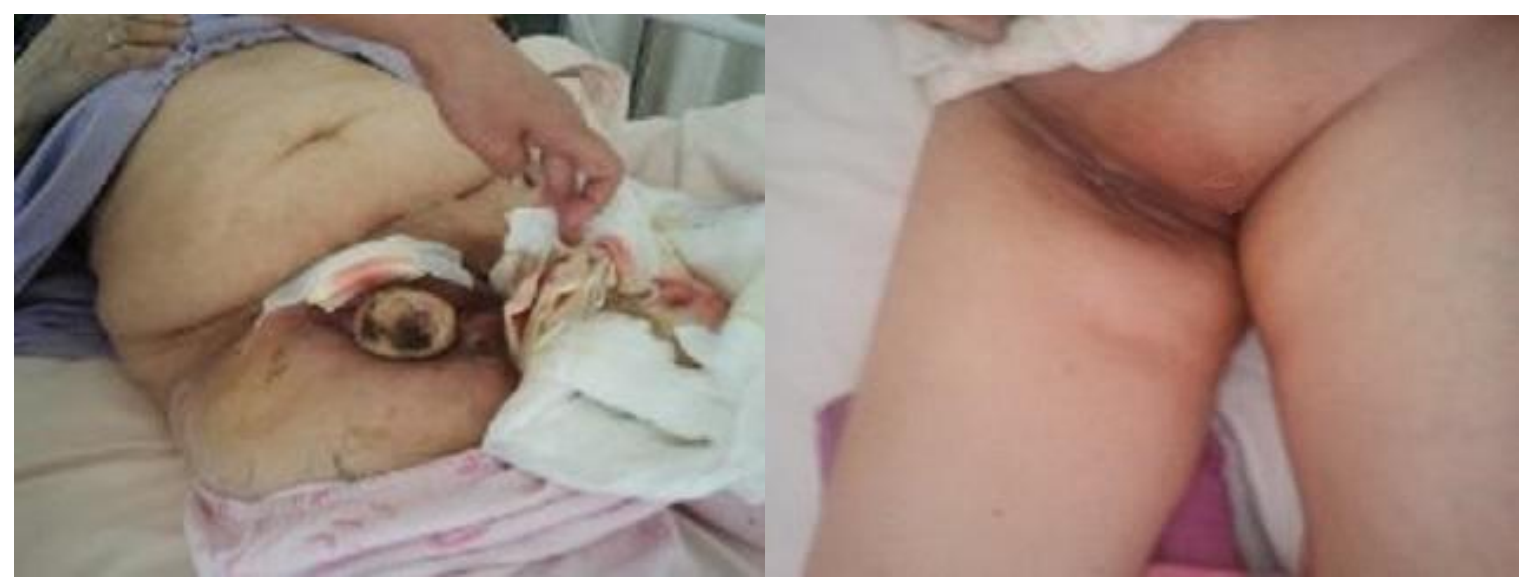

Resim 1: Sağ inguinal ülsere metastatik lenfadenopati. resim 2: Vemurafenib tedavisi sonrası lenfadenopatide gerileme.

bölgesinden yapılan biyopsi sonucu neoplastik hücreler S100 ile diffüz, Melan A ile fokal kuvvetli pozitif olarak MM infiltrasyonuyla uyumluydu.

Posterior akciğer grafisinde yaygın nodüler görünüm izlenmesi üzerine istenen toraks bilgisayarll tomografisinde (BT) sol ana pulmoner arterde üst lob ve alt lob pulmoner artere uzanım gösteren lümeni belirgin daraltan hipodens trombüs materyeli, solda $20 \mathrm{~mm}$ 'ye ulaşan efüzyon, her iki akciğerde en büyüğü yaklaşık $15 \mathrm{~mm}$ olmak üzere çok sayıda metastaz ile uyumlu pulmoner nodül saptand. Beyin manyetik rezonans görüntülemesinde (MRG) metastaz saptanmadi. Pozitron emisyon tomografi- bilgisayarlı tomografisinde (PET-BT) her iki akciğerde büyügü solda paramediastinal yerleşimli 16x8 $\mathrm{mm}$ boyutunda olmak üzere multipl nodülde (SUVm: 9.4), sağ inguinal alandan başlayıp uyluk $1 / 3$ orta kesime uzanan $49 \mathrm{~mm}$ konglomere lenf nodunda (SUVm: 21.7), sağ ayak plantar yüzde cilt üzerinde $15 \mathrm{~mm}$ yumuşak doku lezyonunda (SUVm: 6.8) artmış floro-deoksi-glukoz (FDG) tutulumu izlenir iken sağda periçekal bölgede, çekum komşuluğundan başlayıp iliak bifürkasyona uzanan $71 \mathrm{~mm}$ hipodens lezyonda FDG tutulum izlenmedi. Hastaya dış merkezde metastatik MM 1. basamak tedavisinde 3 kür temozolamid uygulanması sonrası kasık bölgesindeki kitlesinde progresyon izlenmesi üzerine sağ inguinal bölgeye $20 \mathrm{~Gy}$ (4 Gy/g x 5 gün) palyatif radyoterapi (RT) uygulanmıştı.

Hastanın lezyon bölgesinde kötü kokulu akıntısı artarak devam etmesi ve kültürlerde üreme olması üzerine antibiyoterapi uygulanırken tıbbi onkoloji bölümüne konsülte edildi. (Resim 1). İstenen
BRAF mutasyon analizinde ekzon 15 kodon V600E nokta mutasyon saptanması üzerine hastanın enfeksiyon kliniği düzeldikten sonra vemurafenib başlandi. Vemurafenib tedavisinin 2. ayında inguinal LAP metastaz bölgesinde tam yanıt (Resim 2), diğer metastaz bölgelerinde kısmi yanıt elde edildi. Tedavinin 5. ayında hemoptizi ile beraber toraks BT'de mediastinal lezyonlarda progresyon izlendi. Bununla beraber diğer metastaz bölgelerinde kısmi yanıtı devam ediyordu. Hastada hem semptomatik olması hem de izole akciğerde progresyon izlenmesi nedeni ile sol akciğerdeki lokal lezyonuna ve mediastendeki pulmoner artere bası oluşturan lezyonlarına 30 Gy (3 Gy/gün x 10 gün) RT uyguland1. Sistemik hastalığın lokal (akciğer ve mediasten) bölge dışında çok iyi yanıtlı olması nedeni ile vemurafenibe devam edildi. İmmünoterapilerin yanıtlarının uzun sürede ortaya çıkması ve ek olarak akciğer bölgesi dışında iyi yanıt elde edilmesi nedeni ile vemurafenib tedavisine devam edildi. Bir ay sonra hasta hemoptizi nedeni ile kaybedildi.

\section{Tartışma}

BRAF hedefli tedaviler BRAF mutasyonu taşıyan metastatik $\mathrm{MM}$ hastalarında tedavi seçeneği olarak yerini almıştır. Vemurafenib randomize, faz 3 çalışmada $(n=675)$, daha önce tedavi almamış evre IIIc ve IV BRAF mutasyonlu hastalarda dakarbazin ile karşılaştırılmıştır. Ortanca OS, vemurafenib ve dakarbazin kollarında sirası ile 13.6 ay ve 9.7 ay $(\mathrm{p}<0.001)$ iken 12 aylık OS vemurafenib ve dakarbazin kolunda siras1 ile \%56 ve \%44 olarak $(p=0.0001)$ saptanmış. Ortanca progresyonsuz sağkalım (PFS) vemurafenib 
kolunda 6.9 ay ile anlaml olarak daha uzun tespit edilmiş ( $\mathrm{p}=0.0001)$ (5).

Hedefe yönelik tedavilerde kazanılmış direnç tedavi başarısını ve yaklaşımını etkilemektedir. Vemurafenibe direnç hastaların önemli bir kısmında tedavi başlangıcından 6-7 ay sonra görülmektedir (6). TKİ ve biyolojik varyantlarının kullanımında santral sinir sistemi ve/veya ekstrakraniyal bölge progresyonları görülebilmektedir. $\mathrm{Bu}$ progresyonların yaklaşık üçte biri izole progresyonlardır. TKİ tedavilerinde kazanılmış dirençte yaklaşım, progresyon gösteren alanlarda lokal tedavilerin kullanımıyla birlikte TKİ kullanımına devam edilmesi veya tedavinin değiştirilmesi şeklinde olabilir (7). $\mathrm{Bu}$ hasta grubunda lokal tedaviler sonras1 tedavinin devamı, uzun OS ile ilişkili bulunmuştur. Hatta progrese olan hastalarda dahi tedaviye devam edilmesinin sağkalımda olumlu bir prognostik faktör olduğu bildirilmiştir (8). TKİ kullanan küçük hücre dışı akciğer karsinomlu hastalarda hastalık kontrol süresini değerlendiren bir çalışmada lokal progresyonda lokal tedaviler sonrasinda TKI'ye devam edilmesi, tedavi değiştirilmesinden üstün bulunmuştur (OS 39.4 aya karşıllı 17.8 ay, $p=0.02$ ) (9). Nitekim bizim olgumuzda çoğu hastada beklendiği gibi başlangıçtaki çok iyi klinik yanıta rağmen tedavinin 5. ayında izole akciğer progresyonu izlendi. Metastatik MM'de gerek alternatif tedavi seçeneklerinin kisıtlılığı, gerekse alternatif tedavi olabilecek ipilimumabın etkinliğinin uzun sürede ortaya çıkması tedavi yaklaşımımızı etkiledi. Bizim olgumuzda gerek cilt ve gerekse akciğer dişı tulumlarda vemurafenib yanıtı mevcuttu. Biz hastamızda izole akciğer progresyonunu RT ile tedavi etmek suretiyle vemurafenib tedavisine devam ettik.

Diğer bir önemli nokta da hastamızda ilk progresyonda lokal RT sonrası uygulanan vemurafenib ile aynı bölgede tam yanıt izlenmesidir. Literatürde vemurafenib ile eș zamanlı RT uygulanan bazı olgularda cilt toksisitesi artmasına rağmen hastalıkta dramatik yanıtlar bildirilmiştir (10). Bizim hastamızda da ardışık uygulanan RT ve vemurafenib ile RT alanında tam yanıt elde edildi. Vemurafenibin radyoduyarlaştırıcı etkisini araştırmak için yeni çalışmalar yapılması bu konuyu aydınlatacaktır.

Hastamiz hemoptizi gibi tedaviye ikincil de olabilecek bir nedenle kaybedilmiş olsa da hedefe yönelik tedavilerin kullanıldığı hastalarda, izole progresyonlar dışında hastalık kontrolü sağlanan durumlarda lokal tedaviler sonras1 mevcut hedefe yönelik tedavinin devamı akılda tutulmalıdır.

\section{Çıkar çatışması: Yok}

\section{Kaynaklar}

1. Kaufman HL, Kirkwood JM, Hodi FS, et al. The Society for Immunotherapy of Cancer consensus statement on tumour immunotherapy for the treatment of cutaneous melanoma. Nat Rev Clin Oncol 2013;10:588-98

2. Holderfield M, Deuker MM, McCormick F, McMahon M. Targeting RAF kinases for cancer therapy: BRAF-mutated melanoma and beyond. Nat Rev Cancer 2014;14:455-67

3. Curtin JA, Fridlyand J, Kageshita $T$, et al. Distinctsets of genetic alterations in melanoma. N Engl J Med 2005;353:2135-47

4. Bollag G, Hirth P, Tsai J, et al. Clinicalefficacy of a RAF inhibitör needs broad target blockade in BRAFmutant melanoma. Nature 2010;467:596-9

5. McArthur GA, Chapman PB, Robert C,et. al. Safety and efficacy of vemurafenib in BRAF(V600E) and BRAF(V600K) mutation-positive melanoma (BRIM$3)$ : extended follow-up of a phase 3, randomised, open-label study. Lancet Oncol 2014;15:323-32

6. Chapman PB, Hauschild A, Robert C, et al. Improved survival with vemurafenib in melanoma with BRAF V600E mutation. N Engl J Med 2011;364:2507-16

7. Camidge DR, Pao W, Sequist LV. Acquired resistance to TKIs in solid tumours: learning from lung cancer. Nat Rev Clin Oncol 2014;11:473-81

8. Chan MM, Haydu LE, Menzies AM, et. al. The nature and management of metastatic melanoma after progression on BRAF inhibitors: Effects of extended BRAF inhibition. Cancer 2014;Jul 1. doi: 10.1002/cncr.28851

9. Yang JJ, Chen HJ, Yan HH, et al. Clinical modes of EGFR tyrosine kinase inhibitor failure and subsequent management in advanced non-small cell lung cancer. Lung Cancer 2013;79:33-9

10. Baroudjian B, Boussemart L, Routier E. et al. Dramatic response to radiotherapy combined with vemurafenib. Is vemurafenib a radiosensitizer? Eur J Dermatol 2014;24:265-7 